\title{
Direct and Efficient Conversion of Tertiary Thioamides to $S$-2-Oxo Thioesters under Solvent-free Conditions
}

\author{
Hassan Zali Boeini* and Aida Khajeh \\ Department of Chemistry, University of Isfahan, 81746-73441, Isfahan, Iran. *E-mail: h.zali@chem.ui.ac.ir \\ Received January 17, 2011, Accepted February 1, 2011
}

\begin{abstract}
A one-pot conversion of tertiary thioamides to $S$-2-oxo thioesters is reported. Hence, tertiary thioamides were reacted with $\alpha$-halo ketones or acids under solvent-free conditions to produce the corresponding oxo-thioesters in good to excellent yields.
\end{abstract}

Key Words : Acid derivatives, Thioesters, Thioamide, Solvent-free

\section{Introduction}

It is well known that thioesters are important compounds due to their large number of biological activities ${ }^{1-4}$ and huge potential for the applications in drug development, ${ }^{5-9}$ and industry. ${ }^{10-12}$ Also, thioesters have distinct chemical properties compared to ordinary esters ${ }^{13}$ and their enhanced reactivity has been employed successfully in a wide range of synthetic organic reactions. ${ }^{14}$ Therefore, developing a simple and versatile method for the preparation of thioesters is still a challenge in organic synthesis.

The most known approaches to the synthesis of thioesters are concisely reviewed in our recently published article concerning the synthesis of thioesters in water. ${ }^{15}$ More recently, acyloxy phosphonium salts and benzyltriethylammonium tetrathiomolybdate have been successfully applied for the conversion of carboxylic acids to the corresponding thioesters. But this approach utilizes a complex reaction media, somehow expensive reagents, and alkyl halides in the course of reaction. ${ }^{16}$ Very recently thioesters have been synthesized via the reaction of thiols and acid halides promoted by silica gel. ${ }^{17}$

Thioesters also have been prepared by the reaction of thioamides and alcohols in acidic media. ${ }^{18}$ But, these methods restricted to alcohols generating stable carbocations.

Although the latter protocols provide rather efficient access to thioesters, they suffer from the use of corrosive reagents, harsh reaction conditions, expensive catalysts or reagents, and use of unfriendly organic solvents. On the other hand, in the most of previously mentioned methods thiols are used as starting materials, which are very unpleasant and noxious compounds. However, despite the efficiency of the latter methods, the development of solvent-less, efficient, less expensive, and still simpler method for the synthesis of $S$-2oxo thioesters was the major goal of our research. Therefore, we were eager to build up a single-step and rather ecofriendly method for the synthesis of diverse $S$-2-oxo thioesters using thioamides.

Thioamides have been proven to be extremely successful synthons in the organic synthesis and especially in construction of heterocyclic compounds. ${ }^{19}$ Herein, we describe a

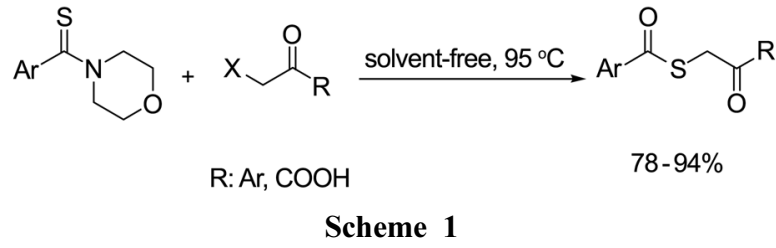

straightforward and versatile method for the conversion of $\alpha$-halo carbonyls to $S$-2-oxo thioesters using thioamides under solvent-free conditions (Scheme 1).

\section{Results and Discussion}

The starting thiomides used in this study could be easily prepared by the Willgerodt-Kindler method. ${ }^{20}$ Our study was started with examining the reaction of (4-chlorophenyl) (morpholino)methanethione $\mathbf{1}$ as a test thioamide with $\alpha$ halo carbonyl 2 and in various reaction conditions to produce the corresponding $S$-2-oxo(4-bromophenyl)ethyl 4chlorobenzothioate $\mathbf{3 a}$ in good yield ( $85 \%$, Table 1 ).

DMF was used at the beginning of our study as solvent for the reaction course. Therefore, a mixture of (4-chlorophenyl)

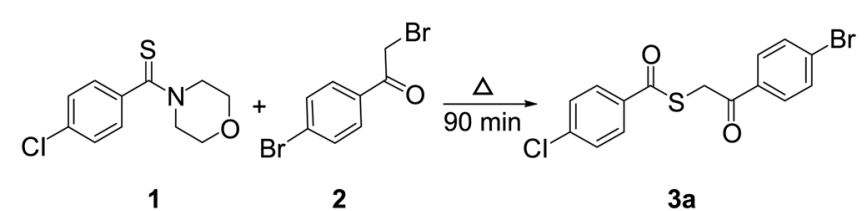

Table 1. Variation of conditions in the synthesis of thioester $\mathbf{3} \mathbf{a}^{a}$

\begin{tabular}{cccc}
\hline Entry & Solvent & Temperature ${ }^{\circ} \mathrm{C}$ & Yield (\%) \\
\hline \multirow{2}{*}{$\mathbf{1}$} & \multirow{2}{*}{ DMF } & 60 & 55 \\
& & 95 & 67 \\
& & $120^{c}$ & 65 \\
$\mathbf{2}$ & $\mathrm{H}_{2} \mathrm{O} / \mathrm{HTAB} / \mathrm{I}^{-}$ & 60 & 15 \\
& & $95^{b}$ & 53 \\
& & $120^{b}$ & 54 \\
$\mathbf{3}$ & Solvent-free & 95 & 85 \\
& & $120^{c}$ & 76 \\
\hline
\end{tabular}

$\overline{a_{\text {thioamide }}(1 \mathrm{mmol}), \alpha \text {-halo ketone }(1 \mathrm{mmol}) .{ }^{b} \text { in reflux condition. }}$ ${ }^{c}$ Formation of colored impurities 
solvent-free

3f, $88 \%$

Scheme 2

(morpholino)methanethione and 2-bromo-1-(4-bromophenyl) ethanone, were dissolved in small amounts of DMF and the reaction mixture was heated at temperatures mentioned in Table 1 for 90 minutes. Thereafter, the reaction mixture was poured in a mixture of ice-water to deposit the crude thioester as a semisolid material which, after crystallization in a suitable solvent $(\mathrm{EtOH})$ the pure compound 3a was afforded in moderate yields (55-67\%). In addition to DMF, water also was examined as a green solvent for the reaction media but the screening results did not show an increase in the yield of thioester product. Our investigations showed that in this condition some hydrolysis of $\alpha$-halo carbonyl starting material to the corresponding $\alpha$-hydroxy carbonyl was occurred, thereby reducing the product yield $\left(95^{\circ} \mathrm{C}\right.$, $53 \%$ ). Surprisingly when the reaction was performed under solvent-free condition, a remarkable increase in the yield of thioester 3a was observed ( $85 \%$, Table 1$)$. It is notable that increasing the reaction times and temperatures higher does not cause an increase in the yield of thioester and our examinations demonstrated that in these conditions the reaction mixture was contaminated with some coloured or tarry materials.

In order to evaluate the scope of the reaction, the presented methodology was applied to the $\alpha$-halo carboxylic acids and our investigation revealed that these $\alpha$-halo carbonyls also work well in the reaction course. (Scheme 2).

The versatility of the method has been confirmed by the successful synthesis of ten structurally diverse thioesters in good to excellent yields (78-94\%) and Table 2 summarizes our results. Our experiments obviously revealed that all kinds of $\alpha$-halo carbonyl could be successfully applied in the course of reaction but better results were obtained with $\alpha$-halo carboxylic acids.

In addition to the simplicity of the method, high yields, and easy work-up, the salient futures of this methodology lie in the fact that the reactions are carried out under solventfree condition. Additionally, isolation and the purification of thioester products are very simple. Moreover, the method is compatible with many substituents such as halogen, alkoxy, dialkylamino, etc., in the substrates.

\section{Conclusions}

In conclusion, herein a simple methodology was reported for the conversion of tertiary thioamides to thioesters under solvent-free conditions, which is expected to be a quite general route for the synthesis of diverse $S$-2-oxo thioesters. Besides being an efficient and easy to perform reaction, the method benefits from using cheap starting materials. Also, isolation and purification of product is straight forward and
Table 2. Efficient synthesis of $S$-2-oxo thioesters using tertiary thioamides

Entry

$\overline{{ }^{a} \text { All products were characterized by IR, and }{ }^{1} \mathrm{H} \text { NMR. }{ }^{b} \text { All yields refer to }}$ pure isolated products.

very simple.

\section{Experimental Section}

General Procedure for the Conversion of Tertiary Thioamides to Thioesters Under Solvent-free Conditions. In a round bottom flask, thioamide $(1 \mathrm{mmol})$ and $\alpha$-halo carbon$\mathrm{yl}$ derivative $(1.2 \mathrm{mmol})$ were heated to melt and heating 
was continued at $95{ }^{\circ} \mathrm{C}$ for 90 minutes. Then the reaction mixture was poured in water $(10 \mathrm{~mL})$ and boiled for 10 minutes with vigorous stirring. After cooling, an oily residue was left which soon solidified to a semi-crystalline mass. Thereafter, the solid was filtered and washed with water (10 $\mathrm{mL})$. Finally the solid compound was recrystallized from $\mathrm{EtOH}(95 \%)$ to afford pure thioesters as white or pale yellow needles with a characteristic odor.

Compound 3a: $\mathrm{mp}$ (EtOH): $128-130{ }^{\circ} \mathrm{C} ;{ }^{1} \mathrm{H}$ NMR (400 $\left.\mathrm{MHZ} \mathrm{CDCl}_{3}\right) \delta 7.96(\mathrm{~d}, J=8.4 \mathrm{~Hz}, 2 \mathrm{H}), 7.92(\mathrm{~d}, J=8.8 \mathrm{~Hz}$, 2H), $7.66(\mathrm{~d}, J=8.8 \mathrm{~Hz}, 2 \mathrm{H}), 7.45$ (d, $J=8.4 \mathrm{~Hz}, 2 \mathrm{H}) 4.54$ (s, 2H).

Compound 3b: mp (EtOH): 115-116 ${ }^{\circ} \mathrm{C} ;{ }^{1} \mathrm{H}$ NMR (400 $\left.\mathrm{MHz} \mathrm{CDCl}_{3}\right) \delta 7.93(\mathrm{~d}, J=8.4 \mathrm{~Hz}, 2 \mathrm{H}), 7.92(\mathrm{~d}, J=8.0 \mathrm{~Hz}$, 2H), 7.65 (d, $J=8.4 \mathrm{~Hz}, 2 \mathrm{H}), 7.32$ (d, $J=8.0 \mathrm{~Hz}, 2 \mathrm{H}), 4.52$ (s, 2H), 2.97 (sep, $J=6.8 \mathrm{~Hz}, 1 \mathrm{H}), 1.28(\mathrm{~d}, J=6.8 \mathrm{~Hz}, 6 \mathrm{H})$.

Compound 3c: $\mathrm{mp}$ (EtOH): $140-141{ }^{\circ} \mathrm{C} ;{ }^{1} \mathrm{H}$ NMR (400 $\left.\mathrm{MHz} \mathrm{CDCl}_{3}\right) \delta 8.14(\mathrm{~d}, J=8.4 \mathrm{~Hz}, 2 \mathrm{H}), 7.97(\mathrm{~d}, J=8.8 \mathrm{~Hz}$, 2H), 7.74 (d, $J=8.4 \mathrm{~Hz}, 2 \mathrm{H}), 7.65$ (d, $J=8.8 \mathrm{~Hz}, 2 \mathrm{H}), 7.64$ (m, 5H), 4.63 (s, 2H).

Compound 3d: $\mathrm{mp}(\mathrm{EtOH}): 125-127{ }^{\circ} \mathrm{C}$; ${ }^{1} \mathrm{H}$ NMR (400 $\left.\mathrm{MHz}, \mathrm{CDCl}_{3}\right) \delta 8.14(\mathrm{~d}, J=8.4 \mathrm{~Hz}, 2 \mathrm{H}), 7.91(\mathrm{~d}, J=8.0 \mathrm{~Hz}$, $2 \mathrm{H}), 7.73(\mathrm{~d}, J=8.0 \mathrm{~Hz}, 2 \mathrm{H}), 7.64(\mathrm{~d}, J=8.4 \mathrm{~Hz}, 2 \mathrm{H}), 7.47$ $(\mathrm{m}, 5 \mathrm{H}), 4.60(\mathrm{~s}, 2 \mathrm{H}), 2.41(\mathrm{~s}, 3 \mathrm{H})$.

Compound 3e: $\mathrm{mp}(\mathrm{EtOH}): 110-112{ }^{\circ} \mathrm{C} ;{ }^{1} \mathrm{H}$ NMR (400 $\left.\mathrm{MHz}, \mathrm{CDCl}_{3}\right) \delta 7.88(\mathrm{~d}, J=8 \mathrm{~Hz}, 2 \mathrm{H}), 7.27(\mathrm{~d}, J=8 \mathrm{~Hz}$, $2 \mathrm{H}), 3.91(\mathrm{~s}, 2 \mathrm{H}), 2.42(\mathrm{~s}, 3 \mathrm{H})$.

Compound 3f: $\mathrm{mp}$ (EtOH): $111-113{ }^{\circ} \mathrm{C} ;{ }^{1} \mathrm{H}$ NMR $(400$ $\left.\mathrm{MHz} \mathrm{CDCl}_{3}\right) \delta 7.93(\mathrm{~d}, J=8.4 \mathrm{~Hz}, 2 \mathrm{H}), 7.47(\mathrm{~d}, J=8.4 \mathrm{~Hz}$, 2H), 3.93 (s, 2H).

Compound 3g: mp (EtOH): 110-113 ${ }^{\circ} \mathrm{C}$; ${ }^{1} \mathrm{H}$ NMR (400 $\left.\mathrm{MHz}^{\mathrm{CDCl}}{ }_{3}\right) \delta 7.92(\mathrm{~d}, J=8.0 \mathrm{~Hz}, 2 \mathrm{H}), 7.33$ (d, $J=8.0$, 2H), $3.91(\mathrm{~s}, 2 \mathrm{H}), 2.97(\mathrm{sep}, J=6.81 \mathrm{H}), 1.28(\mathrm{~d}, J=6.8 \mathrm{~Hz}$, $6 \mathrm{H})$.

Compound 3h: $\mathrm{mp}$ (EtOH): 180-183 ${ }^{\circ} \mathrm{C} ;{ }^{1} \mathrm{H}$ NMR (400 $\left.\mathrm{MHz} \mathrm{CDCl}_{3}\right) \delta 7.75(\mathrm{~d}, J=8.8 \mathrm{~Hz}, 2 \mathrm{H}), 6.74(\mathrm{~d}, J=8.8 \mathrm{~Hz}$, 2H), 3.78 (s, 2H), 2.49 (s, 6H).

Compound 3i: $\mathrm{mp}(\mathrm{EtOH}): 135-136{ }^{\circ} \mathrm{C} ;{ }^{1} \mathrm{H}$ NMR (400 $\left.\mathrm{MHz}^{\mathrm{CDCl}}{ }_{3}\right) \delta 7.68(\mathrm{~d}, J=8.4 \mathrm{~Hz}, J=2 \mathrm{~Hz}, 1 \mathrm{H}), 7.47(J=$ $2 \mathrm{~Hz}, 1 \mathrm{H}), 6.91$ (d, $J=8.4 \mathrm{~Hz}, 1 \mathrm{H}), 3.96$ (s, 3H), 3.94 (s, $3 \mathrm{H}), 3.91$ (s, 2H).

Compound 3j: mp (EtOH): 167-168 ${ }^{\circ} \mathrm{C} ;{ }^{1} \mathrm{H}$ NMR (400 $\left.\mathrm{MHz}, \mathrm{CDCl}_{3}\right) \delta 8.01(\mathrm{~d}, J=8.0 \mathrm{~Hz}, 2 \mathrm{H}), 7.87(\mathrm{~d}, J=8.0 \mathrm{~Hz}$, 2H), $7.75(\mathrm{~d}, J=7.6 \mathrm{~Hz}, 2 \mathrm{H}), 7.51(\mathrm{t}, J=7.6 \mathrm{~Hz}, 2 \mathrm{H}), 7.44(\mathrm{t}$, $J=7.6 \mathrm{~Hz}, 1 \mathrm{H}), 3.91$ (s, 2H).
Acknowledgments. We are grateful to University of Isfahan research council for financial support of this work.

\section{References}

1. Vallari, D. S.; Jackowski, S.; Rock, C. O. J. Biol. Chem. 1987, $262,2468$.

2. Stindl, A.; Keller, U. J. Biol. Chem. 1993, 268, 10612.

3. Dittmann, J.; Wenger, R. M.; Kleinkauf, H.; Lawen, A. J. Biol. Chem. 1994, 269, 2841

4. Stachelhaus, T.; Huser, A.; Marahiel, M. A. Chem. Biol. 1996, 3, 913.

5. Kanda, Y.; Ashizawa, T.; Kakita, S.; Takahashi, Y.; Kono, M.; Yoshida, M.; Saitoh, Y.; Okabe, M. J. Med. Chem. 1999, 42, 1330.

6. Mroszczak, E.; Runkel, R. U. S. Patent 4397 862, 1983; Chem. Abstr. 1983, 99, 146134.

7. Venuti, M. C.; Young, G. M.; Maloney, P. G.; Johnson, D.; McGreevy, K. Pharm. Res. 1989, 6, 867.

8. Greenlee, M. L.; Laub, J. B.; Balkovec, J. M.; Hammond, M. L.; Hammond, G. G.; Pompliano, D. L.; Epstein-Toney, J. H. Biorg. Med. Chem. Lett. 1999, 9, 2549.

9. Olsen, J.; Bjørnsdottir, I.; Tjørnelund, J.; Hansen, S. H. J. Pharm. Biomed. Anal. 2002, 29, 7.

10. Matsumoto, K.; Costner, E. A.; Nishimura, I.; Ueda, M.; Willson, C. G. Macromolecules 2008, 41, 5674.

11. Kricheldorf, H. R.; Schwarz, G. J. Macromol. Sci. A 2007, 44, 625.

12. Kameyama, A.; Kimura, Y.; Nishikubo, T. Macromolecules 1997, 30, 6494.

13. Yang, W.; Drueckhammer, D. G. J. Am. Chem. Soc. 2001, 123, 11004.

14. (a) Johnson, J. S.; Evans, D. A. Acc. Chem. Res. 2000, 33, 325. (b) Fortner, K. C.; Shair, M. D. J. Am. Chem. Soc. 2007, 129, 1032. (c) Gennari, C.; Vulpetti, A.; Pain, G. Tetrahedron 1997, 53, 5909. (d) Kobayashi, S.; Uchiro, H.; Fujishita, Y.; Shiina, I.; Mukaiyama, T. J. Am. Chem. Soc. 1991, 113, 4247.

15. Zali Boeini, H.; Eshghi Kashan, M. Green Chem. 2009, 11, 1987.

16. Gopinath, P.; Vidyarini, R. S.; Chandrasekaran, S. J. Org. Chem. 2009, 74, 6291.

17. Basu, B.; Paul, S.; Nanda, A. K. Green Chem. 2010, 5, 767.

18. (a) Krayushkin, M. M.; Lichitskii, B. V.; Mikhalev, A. P.; Nabatov, B. V.; Dudinov, A. A.; Ivanov, S. N. Russian J. Org. Chem. 2006, 42, 860. (b) Zali Boeini, H.; Mobin, M. Synlett 2010, 2861.

19. (a) Jagodzinski, S. T. Chem. Rev. 2003, 103, 197. (b) Matloubi Moghaddam, F.; Zali Boeini, H. Synlett 2005, 1612.

20. (a) Vogel, A. R. Vogel's Textbook of Practical Organic Chemistry, 5th ed.; Furniss, B. S., Hannaford, A. J., Smith, P. W. J., Tatchell, A. R., Eds.; Longman Scientific \& Technical: Essex, 1989; pp 1054-1055. (b) Zbruyev, O. I.; Stiasni, N.; Kappe, C. O. J. Comb. Chem. 2003, 5, 145. (c) Charette, A. B.; Grenon, M. J. Org. Chem. 2003, 68, 5792. (d) Olsson, R.; Hansen, H. C.; Andersson, C. M. Tetrahedron Lett. 2000, 41, 7947. (e) Polshettiwar, V.; Kaushik, M. P. Tetrahedron Lett. 2006, 47, 2315. 